\title{
Implicación tecnológica del audiovisual para dispositivos móviles. Estado de la cuestión y propuesta de modelos de producción
}

Fernando Galindo Rubio

Profesor de Tecnología Audiovisual en la Universidad Pontificia de Salamanca

Resumen

La evolución de la tecnología digital, cada vez más audiovisual, propone un medio de difusión de contenidos que aporta nuevas perspectivas a la producción: los dispositivos móviles.

Estos medios aportan individualidad en el consumo - un móvil, un receptor - y la posibilidad de iniciar esquemas de comunicación bidireccional. A cambio, exigen un esfuerzo de productoras y antenas, no por adaptar lo ya existente en televisión, sino por crear nuevos formatos y productos para este nuevo paradigma de la comunicación audiovisual.

Así, se repasará el estado de la cuestión - el panorama existente en España en lo que a audiovisual móvil se refiere - y a continuación, se expondrán una serie de propuestas de producción eficientes en función de los géneros audiovisuales clásicos.

Palabras clave:

Audiovisual, tecnología, móvil, digital, vídeo.

Abstract:

The evolution of digital technology, increasingly audio-visual, proposes a way of diffusion of contents that contributes new perspectives to the production: the mobile devices. 
These media contribute individuality in the consumption - one mobile, one person - and the possibility of initiating schemes of bidirectional communication. In other hand, they demand an effort of producers and broadcasters, not to adapt the already existing contents in TV, but to create new formats and products for this new paradigm of the audio-visual communication.

This way, the current moment of the question will be revised - the existing panorama in Spain in what to audio-visual mobile it refers - and later, there will be exposed a series of efficient offers of production depending on the classic audio-visual kinds.

Key words:

Audio-visual, technology, mobile, digital, video.

\section{Introducción}

Que el concepto de televisión como medio exclusivo de transmisión de contenidos audiovisuales se está agotando es un hecho que viene precipitándose desde que alternativas refugiadas en la tercera pantalla - el ordenador - como Youtube, Googlevideo o Photobucket, los programas Peer to Peer, y más recientemente sistemas de compartición y remezcla (Share \& Mix) de contenidos audiovisuales como Jumpcut - recientemente adquirida por Yahoo -, hacen estragos y rompen la linealidad de las parrillas de programación, confiriendo al usuario la posibilidad de crear, compartir y descargar material audiovisual mucho más afín a los gustos y preferencias de la audiencia.

Incluso, proyectos como Joost ${ }^{1}$ (antes Venice Project) albergan la potestad de elegir una selección de contenidos de cualquier canal de televisión del planeta y recibirlo con calidad broadcast desde cualquier rincón del globo consiguiendo que se haga difícil pensar en un sistema audiovisual estático basado en la "tiranía" de los programadores - sometidos éstos

\footnotetext{
Joost es un software en fase de experimentación en el que es necesario solicitar la posibilidad de ser "beta tester". Una vez descargado ofrece un interface en el cual se dispone a pantalla completa (640x480) la posibilidad de visionar amplias selecciones de vídeos de los canales de televisión que participan en el proyecto. Es posible configurar de forma personalizada la lista de canales y de programas disponibles. La web donde se puede solicitar la versión beta del programa es www.joost.com
} 
a los intereses de productores y anunciantes - abriéndose así un nuevo modelo de recepción a la carta en el que casi todos los elementos del proceso comunicativo han de evolucionar, desde el emisor, que ya no hablará a grandes grupos de público, hasta el receptor - individual - pasando por la multiplicación de canales así como innovadores y desconocidos sistemas de control de audiencias y, por ende, nuevas formas de financiación de productos y líneas de distribución.

A todo ello se le suma un nuevo medio, el más personal si cabe, que centra su fortaleza en estar siempre al lado del receptor, la cuarta pantalla, el mobile device, del que ya en 1995 preconizara Nicholas Negroponte en su “Mundo Digital” (Negroponte, 2000:82) que revolucionaría el concepto de comunicación.

Los dispositivos móviles (teléfonos celulares, PDA, reproductores de audio y vídeo, smartphones, ultramobiles, como Origami, o vídeoglasses, como los prototipos de Lumus) están agitando el concepto de audiovisual de una forma que se torna pertinente realizar una reflexión sobre cómo han de ser las estrategias eficaces de comunicación para dispositivos móviles, partiendo de dos hechos relevantes.

Uno, los mismos contenidos que funcionan perfectamente para la televisión no lo han de hacer por fuerza para este tipo de dispositivos. Si tomamos como referencia la medida de 2,5" de superficie (González, 2006:43) para hablar de cuarta pantalla es evidente que la competición con el televisor, cada vez más grande, tecnológicamente más avanzado y ya asentado en nuestra forma de ver la televisión, está perdida de antemano.

Y dos, la comunicación debe volverse personal y personalizada. Si la recepción de la televisión, ampliamente entendida, se produce de forma colectiva, como en su inicio la radio, en torno al dispositivo - el televisor -, la recepción en movilidad ha de buscar la forma de comunicar personalmente, de mi a ti, porque la gran innovación en el fondo de este invento, es que cada sujeto receptor tiene un número único y distinto al cual asociar datos, características, gustos, preferencias... y mediante el cual se puede establecer, por fin, comunicación unidireccional: "Hay soportes, como el teléfono móvil, donde esta identificación es prácticamente inequívoca, porque cada aparato tiene un número asociado (Domingo Santamaría, 2005:201) 
De esta forma, el mensaje, como lo hizo la radio al aplicar la tecnología de transistores y conseguir receptores de radio "de bolsillo", debe buscar la aceptación - y el consumo - desde la consideración del telespectador como alguien en quien se ha pensado y analizado previamente para ofertarle contenidos que se adapten a su perfil de ingesta de contenidos audiovisuales. El contenido audiovisual para móviles debe ser exclusivo, y si se atiende con precisión al significado del término, esto significa que excluya a otros, es decir, que sólo "yo" lo tenga y "tú”, no. Esa puede ser, sin duda, la gran fortaleza de este medio.

Así, en este artículo se repasará el panorama de contenidos audiovisuales que se está ofertando desde las operadoras de telecomunicaciones y que revela el asincronismo existente entre las tecnologías desarrolladas y la reticencia de organismos competentes a implantarlas, así como la escasez de usuarios que han decidido incorporarse a esta nueva forma de comunicación audiovisual.

En segundo lugar, se analizarán dichas tecnologías, las existentes y las venideras, que amplían la posibilidad de producir y difundir mediante dispositivos móviles contenidos audiovisuales.

Posteriormente, este trabajo se centrará en observar la nueva comunicación audiovisual móvil desde un punto de vista particular enfocado en la perspectiva de los géneros clásicos - información, ficción, entretenimiento, publicidad - y desde la integración de los mismos en nuevos formatos complementarios, no sólo entre ellos, sino con productos preparados para ser difundidos por varios medios. Esta revisión tiene como objetivo último proponer alternativas eficientes que superen las carencias que plantea el hecho recurrente en el nacimiento de cualquier medio de trasvasar los contenidos de un medio tradicional al emergente.

\section{1.- ¿Qué comunicación audiovisual se puede recibir en un móvil?}

Como se anticipaba, los contenidos audiovisuales susceptibles de ser recibidos en un dispositivo móvil son menos que lo que teóricamente auguran los desarrollos tecnológicos (muy por delante de la tecnología implantada) y lo que es menos edificante, generalmente son meros trasvases de contenidos audiovisuales televisivos comprimidos en formatos compatibles con los reproductores de vídeo instalados en los terminales. 


\section{1.- Televisión en el móvil}

La mayoría de las operadoras han centrado sus líneas de transmisión de contenidos en la selección de piezas de sus producciones estelares de ficción o entretenimiento ("Aquí no hay quién viva", “Homo zapping”...) que el usuario debe descargar desde su terminal UMTS previo pago. Así mismo, se seleccionan y transforman en archivos compatibles las noticias más impactantes de los servicios informativos $(C N N+, A 3 T V \ldots)$ de la cadena concertada y se ponen a disposición del usuario. En este apartado cabe destacar la apuesta generalizada de todas ellas por la inclusión de un apartado dedicado explícitamente a la descarga de la imagen de los goles de los equipos de fútbol de la Liga.

Esta línea de actuación, sin embargo, tiene su fundamento en una clara estrategia de marketing para conseguir acaparar un mayor número de abonados a la operadora que bajo el concepto de televisión "en la palma de su mano" engrosen los verdaderos beneficios de las compañías: las llamadas de voz y los mensajes cortos SMS.

Incluso una de las operadoras, Vodafone, recientemente, transfiere su contenido premium, Digital +, al móvil, iniciando así una nueva apuesta publicitaria basada en la exclusividad del servicio. Esta oferta es reflejo de otras acciones similares que se están desarrollando en Europa como el servicio BT-Movio ofrecido por la operadora inglesa British Telecom que ofrece los canales BBC-One, ITV1 y Channel 4 a los usuarios que lo contraten.

El problema que se suscita y que en gran parte genera la redacción de este trabajo es que son contenidos para ser vistos en pantallas de televisor cuyos tamaños oscilan, de forma masiva, entre las 21 y las 37 pulgadas, muy lejos de las $2 ` 5$ referidas al principio de este artículo como máximo establecido de forma convencional para definir un dispositivo móvil.

Esta diferencia genera una frustración en el usuario que a su vez produce dos efectos negativos: uno, no volver a descargar los productos anunciados; dos, sensación de no haber invertido correctamente el dinero que supone la descarga, siendo éste, junto al desajuste entre el servicio contratado y el percibido (fundamentalmente en el ancho de banda disponible) los dos datos que explican la notoria escasez de abonados a la tecnología $3 G$ en nuestro país. 


\section{2.- Descarga de vídeos}

Como extensión del apartado anterior, se producen contenidos fasciculados para ser recibidos en este tipo de dispositivos. Series de ficción como la pionera en España, Supervillanos, dispuesta por Amena (ahora Orange), encontraron cierta respuesta en el público en sus primeros capítulos, descendiendo al final de su emisión considerablemente el interés entre usuarios, desencantados por una serie audiovisualizada para ser consumida en un televisor (finalmente La Sexta, emitió su contenido íntegro, con un discreto índice de audiencia), y productores, que no encontraron en esta opción un reclamo sólido para atraer abonados al contrato de datos.

24 Horas: Conspiración y otras secuelas refundadas de sus hermanas mayores y denominadas mobisodes, continuaron esta trayectoria irregular sin conseguir enganchar a un público que, probablemente no percibe el beneficio de ver una serie de televisión en unas condiciones de recepción variables y, normalmente, peores que en un televisor.

Sí han tenido más éxito, sobre todo en un público más joven y apasionado, la descarga de vídeoclips musicales, constituyéndose desde ahora este elemento en una herramienta más de promoción de los artistas a la vez que un más que cuestionable intento de acabar con la piratería de Internet o el Top Manta.

Algunos medios de comunicación digitales como Marca Digital trasladan sus innovaciones multimedia, como MarcaToons, al terreno de la movilidad, pero, curiosamente, por ver el mismo producto que está colgado de forma gratuita en la red y cuya descarga desde un ordenador conectado a un servicio $A D S L$, es excelente en cuanto a tiempos de bajada y reproducción, su descarga por terminal móvil es un servicio de pago, su recepción lenta y la reproducción dependiente de las características del terminal.

Todo este panorama de descargas de vídeo conforman un escenario en el que se observa que la mayoría de las opciones no son fines comunicativos en sí mismo, sino meras estrategias de marketing para fidelizar clientes o ganar adeptos bien a la compañía telefónica que los suministra, bien al medio de comunicación que los oferta o enfocados a la promoción de otro bien o servicio ajeno al propio producto en sí mismo. 
En esa línea estaría la reciente propuesta de Telefónica móviles de emitir la serie de ficción “En buena compañía" para abanderar un proyecto de convergencia digital por el que una serie producida para la televisión estará disponible en otros soportes como son TV digital interactiva, descargas digitales en Internet y teléfono móvil. La serie consta de doce capítulos en los que, con una trama de ficción cómica y entretenida, se reflejarán las utilidades de las nuevas tecnologías.

Así, son muy pocas las opciones en las que se piensa en comunicación como fin en sí mismo al hablar de audiovisual móvil. El fenómeno emergente de los movlogs, blogs generados con el móvil para ser recibidos en el móvil, sería uno de esos pocos casos en los que toda la estrategia está enfocada hacia la eficacia comunicativa. Un movlog es un producto audiovisual que basa su interés en la fasciculación de contenidos en directo, en tener pendiente a una audiencia mediante un guión que está por escribir y del que te puede llegar la posibilidad de descargar capítulos en cualquier momento y situación.

\section{3.- Videomensajes}

Otro contenido audiovisual relevante es el videomensaje, consistente en una evolución del mensaje con fotografía que se produce merced a la llegada del estándar de compresión $3 g p^{2}$ que logra comprimir drásticamente un vídeo bien producido con el propio dispositivo de captura de imágenes del celular, o bien adaptando un clip de vídeo estándar a este formato, de forma que permite enviar hasta diez segundos de vídeo entre terminales encapsulados en un mensaje multimedia MMS.

Este formato, cada vez con más auge entre los usuarios no supone la adhesión a un nuevo contrato de servicios UMTS, sino que sólo precisa de la necesidad de disponibilidad de un reproductor de vídeo en el terminal receptor del mensaje, observándose como principal limitación la escasa duración del vídeo mensaje.

\footnotetext{
"El 3gp se basa en una compresión interframe ajustada al estándar MPEG-4 cuyos resultados son archivos con una resolución de 176x144 pixels (QCIF) o 128x96 pixels (sub-QCIF) a 15 frames por segundo para un ancho de banda de $64 \mathrm{~Kb} / \mathrm{s}$ para la señal de vídeo; y compresión MP3 (AMR) en un ancho de banda de 12,2Kb/s para la pista de audio". (Galindo 2005:131)
} 
Prueba de esa proliferación de mensajes, sobre todo entre el público más joven, es el fenómeno de la bofetada feliz, consistente en grabar y difundir acciones vejatorias o violentas, que tanta polvareda ha levantado, y que tan injustamente pone en tela de juicio al desarrollo tecnológico, escondiendo otras miserias del desarrollo social de la especie humana. Tal es el caos, que en Francia se ha aprobado recientemente una ley que prohíbe a todo aquel que no sea reportero profesional grabar y distribuir imágenes violentas.

Por otra parte, y asociado al formato de difusión de los mensajes de vídeo ha aparecido recientemente youtube mobile, un portal para compartir vídeos en formato 3gp, similar al youtube original. Esta opción de intercambio de información audiovisual puede ser una excelente opción para dinamizar la producción y difusión de este tipo de contenidos en un futuro entre el gran público, como lo ha sido, sin duda, su hermano mayor.

\subsection{Televisión Digital Terrestre en el móvil (DVB-H)}

Una de las grandes apuestas de las cinco partes promotoras de la tecnología móvil - gobiernos, operadoras, fabricantes de terminales, desarrolladoras de software y productoras de contenidos audiovisuales - es la posibilidad de recibir la incipiente televisión digital terrestre (TDT) en directo, en el dispositivo móvil, mediante la tecnología denominada $D V B-H$ (Digital Vídeo Broadcast-Handheld ${ }^{3}$.

Esta idea, basada en el aprovechamiento sinérgico de redes establecidas y contenidos ya producidos, beneficioso para gobiernos y televisiones; avance generacional en el desarrollo tecnológico, estratégico para fabricantes y desarrolladores; y nuevo servicio añadido -de pago,

\footnotetext{
" $D V B-H$ se define como un sistema donde la información se transmite en forma de datagramas $I P$. La tecnología de división del tiempo se utiliza para reducir el consumo de energía en terminales de mano pequeños. Los datagramas $I P$ se transmiten como ráfagas de datos en pequeños intervalos de tiempo. El cliente del receptor se enciende únicamente en el intervalo de tiempo en el que la ráfaga de datos de un servicio seleccionado está en el aire. En este breve período de tiempo se reciben datos a gran velocidad, que pueden almacenarse en un búfer. Este búfer puede almacenar las aplicaciones descargadas o reproducir secuencias en vivo. El ahorro de energía logrado dependerá de la relación entre el tiempo de encendido y de apagado. Si hay aproximadamente diez o más servicios de ráfagas en una secuencia $D V B-H$, el ahorro de energía del cliente podría ser del 90\%”. Comunicado de prensa de Digital Video Broadcasting.org. Disponible el 20/04/07 en: http://www.dvb.org/documents/press-releases.
} 
por supuesto - apetecible para operadoras, no hace sino empañar, de forma transitoria, el panorama del audiovisual móvil.

La idea de recibir los mismos contenidos que se reciben en un monitor de gran superficie en condiciones favorables de atención (sofá, tranquilidad, momentos de relax...) en un monitor de apenas quince centímetros cuadrados de superficie se postula en contra de cualquier lógica de la recepción audiovisual y la ya mencionada tendencia a la autoprogramación por parte del usuario.

De hecho, y aunque las tres operadoras presentan como exitosas sus conclusiones sobre las pruebas piloto realizadas en Zaragoza (Amena) ${ }^{4}$, Madrid y Barcelona (Telefónica móviles) ${ }^{5}$ y Sevilla $(\text { Vodafone })^{6}$, los datos son, en ocasiones, muy variables entre sí, por ejemplo, respecto al tiempo diario de utilización (desde los 16 minutos de media para Telefónica a los 38 para Vodafone)

Estos mismos datos arrojan similitudes en lo fundamental para los promotores, llegando a expresar en todos ellos una alta satisfacción sobre el uso y posible recomendación del servicio. Así, el informe de Telefónica explicita:

"Más del 55 por ciento de los usuarios que han explorado la TV digital, en el terminal Nokia 7710, dicen que seguirían usándolo aunque tuvieran que pagar por él, e incluso que pagarían alrededor de 5 euros por una oferta variada de canales constituida por un paquete básico más algún canal Premium. Además, casi un 75 por ciento de estos mismos usuarios recomendarían a otros que utilizaran el servicio."7

4 La información publicada sobre este estudio de la compañía Amena se puede encontrar en http://www.20minutos.es /noticia/104612/0/amena/dvb-h/telefonia/ (disponible abril 2007)

5 Sobre el estudio de Telefónica móviles ver: http://www.vnunet.es/Actualidad/Noticias/ Comunicaciones/Telefonía/20070309056 (disponible abril 2007)

${ }_{6}$ Los datos sobre el estudio de Vodafone, en http://www.vodafone.es/ Vodafone/LaCompanya /NotaSalaPrensa/0,3203,28240,00.html

7 Estudio de Telefónica Móviles. http://www.vnunet.es/Actualidad/Noticias/ comunicaciones/ Telefonía / 20070309056 
Y el de Vodafone: "Así, las principales conclusiones indican que este servicio es considerando muy o bastante interesante por el $72,8 \%$ de los participantes y que un $80 \%$ además, lo recomendarían."

En cuanto a los contenidos preferidos por los usuarios, las tres operadoras se ponen de acuerdo en afirmar que "es destacable, así mismo, que los usuarios de TV en el móvil se han decantado más por el seguimiento de informativos, series y magazines” ${ }^{\text {” }}$ siendo esta percepción contradictoria con otras expresadas en los mismos informes: "La experiencia, que se ha realizado con tecnología DVB-H, ha demostrado, según sus impulsores, que los usuarios prefieren contenidos específicos y adaptados a tiempos de visualización menores, complementados con servicios interactivos con la programación”"10.

Pero sin lugar a dudas, la idea que se propone como denominador común es hacer patente el alto porcentaje de usuarios que declara que pagaría por el uso de este servicio.

Sin embargo, atendiendo a un informe independiente realizado en febrero de 2007 por la consultora DNXGroup y titulado "Mobile TV: tendencias en España"11 se ponen en tela de juicio algunas de estas conclusiones, ya que en este estudio del que sí se ha hecho público su contenido íntegro, refleja que el 85\% de los usuarios de móviles no estaría dispuesto a pagar por este servicio ya que el actual sistema de cuotas de descarga (el previsto para la DVB-H) genera sensación de pérdida de control sobre el gasto.

Del mismo modo, se expresan diferencias en los contenidos. Según esta consultora, los preferidos que los españoles desearían ver en sus móviles, son entre los hombres, los contenidos eróticos y deportivos, y entre las mujeres, entrevistas a famosos y telenovelas.

Estas contradicciones se corroboran aún más, si cabe, si se atiende a lo vertido en foros del ámbito de los consumidores, en los cuales queda más que patente la indisposición inicial a pagar

8 Estudio de la operadora Vodafone. http://www.vodafone.es/Vodafone/LaCompanya /NotaSalaPrensa/ $0,3203,28240,00 . \mathrm{html}$

9 Ibid.

${ }^{10}$ Ibid.

${ }^{11}$ DNX GROUP “Mobile TV. Tendencias en España”, DNXGroup, Barcelona, 2007. 
un coste añadido por un servicio que es gratuito en el televisor del hogar. Así lo reitera el periodista de la conocida bitácora gadgetoblog, Ángel Jiménez de Luis: ${ }^{12}$

Como última referencia hacia las conclusiones de dichos estudios, cabe destacar algo que llama poderosamente la atención y es la coincidencia que tanto el de Vodafone como el de Telefónica expresan sobre las circunstancias de uso del servicio, situando ambos el lugar preferente de recepción, curiosamente, el hogar, templo sagrado de la segunda pantalla. Telefónica: "En la mitad de los casos, la oferta de televisión en el móvil se ha visto desde casa"13; Vodafone: "La mayoría de los encuestados, integrantes del piloto, han expresado que han visto la TV en el móvil estando en su casa (como alternativa a la TV convencional)." ${ }^{14}$

En definitiva, la posible llegada de la $D V B-H$ se plantea, al igual que la $T D T$, como un servicio transitorio que pretende ser utilizado por las cinco partes promotoras como anzuelo hacia el desembarco del audiovisual en el móvil, hecho éste que permitiría financiar y rentabilizar productos audiovisuales, redes de comunicación y estrategias comerciales de las empresas implicadas.

En este sentido, ya se habla de la irrupción de una nueva forma de transmisión de la TDT para móviles. La OFDM (Orthogonal Frequency Division Multiplexing), "que al parecer permite una más que aceptable calidad con receptores en movimiento más aún empleando la variante 8K, la elegida en España. Como siempre habrá que esperar a ver qué ocurre. Si por desgracia triunfa el deseo de aumentar ganancias, frente al cada vez más denostado servicio público, deberemos esperar a que algún avispado fabricante oriental ponga en el mercado un nuevo

\footnotetext{
12 "Cuando el pasado 3GSM acabó la prueba piloto de Telefónica, Nokia y Abertis para llevar la televisión en directo al teléfono crucé los dedos para que fuera la última vez que se escuchase hablar de una idea con tan poco futuro (...). Yo para estas cosas tengo mis propios estudios, que son los que hago entre familiares y amigos, y no conozco a ninguno dispuesto a pagar todos los meses por algo que ven gratis en casa, con mejor calidad y más grande. Además, a ninguno se le ocurre cuándo podría ser un buen momento para verla — ¿en el trayecto de vuelta a casa? (...). La industria de la televisión está cambiando a ritmo acelerado hacia la programación personal. Preferimos descargar de la red y montarnos la tele a la carta pero aquí están estos señores con el viejo concepto de emisión 'de uno para muchos.” (Jiménez de Luis, 2007)

${ }^{13}$ Estudio de Telefónica Móviles. Op. cit.

${ }^{14}$ Estudio de la operadora Vodafone. Op. cit.
} 
teléfono asequible con receptor TDT incorporado. Esto sí será verdadera televisión en el móvil y, además, gratis"15.

De hecho, según la misma publicación pero en su boletín electrónico, se anuncia que Nokia "tras mantener conversaciones con Samsung, habría llegado a un acuerdo para trabajar conjuntamente en el impulso de estándares abiertos en televisión móvil, con el objetivo de alentar una mayor adopción de los servicios de programación de televisión móvil. Nokia ha declarado que planea crear sus productos móviles con los mismos estándares de su sistema de servicios de red" 16

Sin embargo, y como ya se ha comentado, no parece ser el modelo idóneo de producción audiovisual para móviles desde varios puntos de vista relevantes: la falta de competitividad con el televisor por las circunstancias de recepción, la poca eficacia de los mensajes largos y audiovisualizados para televisores de gran tamaño, la carestía del servicio y la regresión a tiempos pasados que supondrá seguir ceñido a una programación igual para todos los telespectadores

En definitiva, y tras haber repasado el panorama audiovisual existente en lo referente a la consideración del dispositivo móvil como medio de comunicación emergente, se podría deducir un notorio pesimismo a la luz de los datos expuestos. Sin embargo, esta actitud apocalíptica no es más que el reflejo de la falta de atención a las posibilidades que esta nueva comunicación presenta y del intento urgente de amortizar las costosísimas inversiones en tecnología desarrolladas. Como se leerá en adelante, más bien al contrario, la simiente de este trabajo es la firme convicción de que aparece en el potencial expresivo del individuo un nuevo y apasionante modo de comunicar audiovisualmente, capaz de complementar de forma innovadora la inaugurada por Internet, época de la comunicación cíclica, que supera de este modo los esquemas tradicionales de comunicación vertical descendente.

\footnotetext{
15 "Editorial", Video Popular, no 122, Abril 2007, p5.

16 "Newsletter", vpnews, 2-V-2007
} 


\section{2. ¿Qué tecnologías están implicadas en la comunicación audiovisual móvil?}

Inevitable en todo trabajo de análisis de formas comunicacionales se ha convertido repasar, aunque sea de forma sucinta, las tecnologías que soportan esa comunicación, ya que en función de su desarrollo, evolucionan los usos, y en función de éstos, nacen nuevas ideas y formas de comunicar.

En este epígrafe pues, se desglosan las tecnologías actuales - aún con el riesgo que supone el ser consciente de que lo que hoy se escribe, en el momento de ser impreso este artículo, estará obsoleto - y se abre la ventana a las nuevas propuestas en desarrollo que ya están siendo probadas en otros países con más inquietud - y financiación - tecnológica como Japón o Estados Unidos.

\subsection{Tecnologías móviles actuales}

En la tabla I se exponen los principales sistemas de telefonía móvil que coexisten en el momento de redactar este trabajo. La lectura clara que se puede realizar de la misma es que el aumento del ancho de banda es el motor de los cambios en este periodo en el que se encuentra la tecnología, tiempo de desarrollo hacia un momento en el que la disponibilidad de descarga de datos no sea un inconveniente a tener en cuenta

Mientras tanto, se observa cómo las tecnologías apuntadas en las filas inferiores de esta tabla son más experimentales que reales, y de la misma manera que sucedía con la aplicación de la $D V B-H$, pese a que las operadoras emitan informes, estudios y comunicados de prensa anunciando la inminente llegada de dichos desarrollos, - “Telefónica Móviles hace realidad HSDPA”17 - lo cierto es que, como se apunta en el informe de DNXGroup, "sólo el 41\% de los usuarios afirman tener reproductor de vídeo, y de ellos, sólo la mitad dispone de tecnología 3G/UMTS ${ }^{18}$.

Si se tiene en cuenta, que el gran problema a superar es que los archivos de vídeo "pesan" demasiado, el panorama es que faltan aún algunos años para conseguir que se establezca una

\footnotetext{
${ }^{17}$ Estudio de Telefónica Móviles. Op cit.

${ }^{18}$ DNX GROUP. Op cit. p.15
} 
estructura comunicativa real y eficaz en la que se pueda construir un sistema comunicativo audiovisual generalizado y eficaz.

\begin{tabular}{|c|c|c|c|c|c|}
\hline Tecnología & $\begin{array}{l}\text { Ancho } \\
\text { de banda }\end{array}$ & $\begin{array}{l}\text { TV en } \\
\text { el móvil }\end{array}$ & $\begin{array}{l}\text { Descarga } \\
\text { de vídeo } \\
\text { (WAP) }\end{array}$ & $\begin{array}{l}\text { Vídeo } \\
\text { mensaje } \\
\text { (MMS) }\end{array}$ & $\begin{array}{l}\text { Televisión } \\
\text { digital } \\
\text { terrestre } \\
\text { (DVB-H) }\end{array}$ \\
\hline $\begin{array}{c}\text { GSM } \\
\text { (Global System Mobile) [2G] }\end{array}$ & $\begin{array}{c}9,6 \mathrm{~kb} / \mathrm{s} \\
\text { (up \& down) }\end{array}$ & NO & NO & NO & NO \\
\hline $\begin{array}{c}\text { GPRS } \\
\text { (General Packet Radio } \\
\text { Service) }[2.5 \mathrm{G}]\end{array}$ & $\begin{array}{c}114 \mathrm{~kb} / \mathrm{s} \\
\text { down - } \\
56 \mathrm{~kb} / \mathrm{s} \mathrm{up}\end{array}$ & $\mathrm{NO}$ & SI & SI & NO \\
\hline $\begin{array}{c}\text { EDGE } \\
\text { (Enhanced Data rates for } \\
\text { GSM Evolution] }\end{array}$ & $\begin{array}{l}\text { Hasta } 384 \\
\text { kb/s } \\
\text { (up\&down) }\end{array}$ & $\mathrm{NO}$ & SI & SI & NO \\
\hline $\begin{array}{c}\text { UMTS } \\
\text { (Universal Mobile } \\
\text { Telecommunication } \\
\text { System) }[3 \mathrm{G}]\end{array}$ & $\begin{array}{l}\text { Hasta 2Mb/s } \\
\text { (up\%down) }\end{array}$ & SI & SI & SI & NO \\
\hline $\begin{array}{c}\text { HSDPA } \\
\text { (High Speed Downlink } \\
\text { Packet Acces) [3.5G] }\end{array}$ & $\begin{array}{c}14 \mathrm{Mb} / \mathrm{s} \\
\text { down - Hasta } \\
1 \mathrm{Mb} / \mathrm{s} \mathrm{up}\end{array}$ & SI & SI & SI & SI \\
\hline $\begin{array}{c}\text { HSUPA } \\
\text { (High Speed Uplink Packet } \\
\text { Acces) }[3.75 \mathrm{G}]\end{array}$ & $\begin{array}{c}14 \mathrm{Mb} / \mathrm{s} \\
\text { down - Hasta } \\
5 \mathrm{Mb} / \mathrm{s} \mathrm{up}\end{array}$ & SI & SI & SI & SI \\
\hline
\end{tabular}

Tecnologías disponibles. Tabla elaborada a partir de los datos extraídos de la obra Sistemas de Telefonía (Huidobro y Conesa, 2006:477-495) 


\subsection{Tecnologías móviles futuras}

Ahondando en esa utopía necesaria, los desarrolladores de tecnologías van más allá, presentando lo que ya se denomina cuarta generación de telefonía móvil (4G), incluso, ya hay fecha prevista para su implantación en Estados Unidos (2007) y Japón (2010), aún sin saber cuáles serán las especificaciones reales de este sistema, basado aún en el deseo más que en la realidad.

Al parecer $4 G$ haría referencia a un sistema global de telefonía móvil basado en protocolos de Internet concediendo a los usuarios un ancho de banda en movimiento de hasta $100 \mathrm{Mb} / \mathrm{s}$ y de $1 \mathrm{~Gb} / \mathrm{s}$ en reposo. El WWRF (Wireless World Research Forum) define 4G como:

una red que funcione en la tecnología de Internet, combinándola con otros usos y tecnologías tales como Wi-Fi y WiMAX. La 4G no es una tecnología o estándar definido, sino una colección de tecnologías y protocolos para permitir el máximo rendimiento de procesamiento con la red inalámbrica más barata. ${ }^{19}$

Parecería de este modo, en definitiva, que el sueño está cerca de convertirse en realidad, sin embargo y como se hace hincapié en una de las principales webs de referencia en el desarrollo de aplicaciones para telefonía móvil - awaves.com - "To broadcast TV to mobile devices a number of issues have to be addressed, such as managing battery life and handling situations not present in normal TV reception, for example outdoor, pedestrian and inside a moving vehicle". ${ }^{20}$

\section{Estrategias en función de los ámbitos de producción}

En la línea de lo expresado anteriormente, se aborda ahora la tarea de repasar los tres grandes grupos de la producción audiovisual: información, ficción y entretenimiento, al que se le suma para la elaboración de este trabajo el ámbito publicitario, ya que, como se verá en detalle, representa en este contexto todo un nuevo campo de experimentación en comunicación audiovisual.

\footnotetext{
${ }^{19}$ Definición de 4G extraída de la web del mencionado organismo: http://www.wireless-world-research.org/

${ }^{20} \mathrm{http}: / /$ www.awaves.com/dvbh/flashok.htm disponible el 13/04/07
} 


\subsection{Informativos. La era del paparazzi universal.}

Cuando alguien imagina el término "últimas noticias" en un móvil, suele hacerlo pensando en un ejecutivo de gran empresa que en su ajetreada agenda no encuentra esos tres cuartos de hora que dura un informativo de televisión para estar ¿informado? - quizá la televisión nunca fue un medio informativo, sino ilustrativo -, ni siquiera tiene tiempo de escuchar uno de los veinticuatro boletines que alguna de las numerosas emisoras de radio lanzan al espacio radiofónico: su única solución es ver las noticias en el móvil. Si el trabajo de este hombre de negocios dependiese de la información que recibe, lo perdería pronto si usa un dispositivo móvil para recibir las noticias. No por desinformación, sino porque las circunstancias de recepción y de descarga de los videomensajes (vídeonoticias) acabarían con su paciencia y lo conducirían inevitablemente a un lugar apropiado con un monitor de televisión donde poder observar sin más perplejidad que la habitual los horrores del último conflicto bélico.

Sin embargo hay vida más allá del trasvase de noticias del televisor al móvil, que como ya se ha repetido varias veces, no deja de ser una estrategia mercantilista de las partes implicadas en el desarrollo tecnológico.

El dispositivo móvil obtiene su fuerza de la correspondencia inequívoca de un número de teléfono con un receptor y de su doble condición de emisor - receptor, es decir, es un vehículo de ida y vuelta, de down \& up.

La primera característica ya se emplea, segmentando al público receptor en función de sus gustos o preferencias, que se hacen coincidir con las secciones del informativo: deportes, nacional, internacional, sucesos, economía..., y a cada terminal le llegan piezas de la sección escogida. Estas piezas proceden, una vez más, del acto de comprimir el minuto y medio de noticia televisada al formato específico de recepción en movilidad. Amén de las mencionadas dificultades propias de la recepción del dispositivo, una noticia descontextualizada de su precedente y su sucesora, no tiene, como decía Requena al exponer las claves del macrodiscurso audiovisual, sentido completo. $\mathrm{O}$, ¿un informativo en televisión es una mera yuxtaposición de piezas estancas? 
La segunda característica, la bidireccionalidad del medio, significa que el dispositivo puede recibir contenidos, pero también puede servirlos a los demás. Y es ahí donde puede tener un futuro innegable si se le sabe sacar provecho.

En Valencia, en 2003, en el canal autonómico, Vicente Bevia y Josep Lluis Muñoz, dos ingenieros de telecomunicaciones empeñaron su palabra y su tiempo en conseguir algo que parecía una perogrullada, que cada reportero de la sección de informativos portase un dispositivo móvil con cámara de vídeo, desde el que pudiese enviar imágenes en directo desde cualquier punto, incluso su propia imagen simulando una entradilla. Es decir, aprovechar la videollamada y el videomensaje para lograr algo tan jugoso para los ejecutivos como los descensos exponenciales de los gastos de producción. Y en el fondo, algo mucho más importante, la posibilidad real de estar presente en cada acontecimiento en el preciso momento en el que se está desarrollando. Las cámaras siempre llegan un ratito después -salvo en la guerra en directo y lo del $11-S$-.

Algo después, una empresa desarrolladora de software, Createcna, cogía el sueño de estos ingenieros y desarrollaba un producto capaz de recibir la señal de varios dispositivos móviles y convertirla al formato $P A L$ para ser emitida en directo por un canal de televisión. Se hicieron pruebas y funcionó. Esto suponía abrir una brecha en los modelos de producción: menor inversión en equipos, cada reportero puede ir sólo e incluso filmar sus propios directos. Pero también incipientes debates: en la calidad de la emisión ¿vale todo? ¿Es preferible que haya imágenes aunque su calidad sea mala, a que no las haya?

De todo esto se puede desprender una cuestión sobre la que se debe reflexionar: ¿y si cada individuo que posea un terminal móvil fuera capaz de emitir en directo imágenes de acontecimientos? Sería la era del paparazzi universal. El potencial informativo que se desprendería de esta idea es tan abrumador como lo supuso en su momento Google Earth: todo el planeta a un click.

Ya hay precedentes, de hecho, en los grandes atentados de este siglo, de periodistas de móvil, que grabaron dichos horrores en un momento en el que era imposible el acceso a estas imágenes de las cámaras convencionales de televisión. Y dichas imágenes, aunque carentes de 
calidad técnica y con dudosa destreza de sus autores, dieron la vuelta al mundo por su incuestionable valor informativo. Si en el medio radio, el móvil ha multiplicado la capacidad de realizar directos en gran medida, en televisión puede llegar a ser un elemento de transmisión de contenidos calientes excepcional.

De hecho, ya hay medios de comunicación en Internet como "Oh my news Internacional” 21 en Corea, que propone el periodismo participativo a través de dispositivos móviles como forma de funcionamiento, recibiendo más de un millón de visitas diarias y con la colaboración de cerca de "30.000 citizen reporters". Si bien, es necesario aclarar, que por el momento este medio sólo se alimenta de contenidos textuales.

En España acaba de surgir desde el sitio web del diario El País, “yo, periodista”, que en palabras textuales, anima al lector "a construir ELPAIS.com. Si has sido testigo de alguna noticia, envíanosla y nosotros la publicamos. Puedes mandarnos textos, fotos, vídeos o documentos. Ahora los lectores de ELPAIS.com se convierten en periodistas"22.

Los periodistas no deben preocuparse por este tipo de propuestas, al contrario, ya que en ella encontrarán una nueva y gratuita agencia de información desde donde realizar nuevos y más profundos desarrollos ${ }^{23}$.

\subsection{Ficción. Mobisodes o caballos regalados.}

Retomando argumentos ya expuestos, se hace difícil pensar que la apuesta de las productoras de ficción sean los dispositivos móviles, ya que no forman parte del espectáculo y la grandiosidad del séptimo arte. El móvil no es el mejor medio donde apreciar la increíble inversión de "los 300", emocionarse con el último beso de Julia Roberts y Richard Gere, o estremecerse con la tensión del "Resplandor".

${ }^{21}$ http://www.periodismo.uchile.cl/ contintanegra/2005/5/blogs.html, Mayo 2007

22 http://www.elpais.com/yoperiodista, Mayo 2007

23 "La función del periodista, en este caso, es ver el perfil de la información, comprobar si las fuentes son verdaderas o la información es veraz. El periodista, en el sentido del periodismo ciudadano, cumple la función de editor, en ningún caso el periodismo va a desaparecer, al contrario, los periodistas somos quienes controlamos la información” (SANDOBAL , 2007) 
Hay que buscar nuevas formas de entender la ficción si ésta se quiere trasladar al móvil. Como suele suceder, cuando un medio nace, la industria cinematográfica también quiere que éste sea su nuevo medio. Legítimo, pero carente de sentido en este caso, si se vuelve a producir el trasvase de contenidos. Las pruebas están ahí: nada relacionado con la ficción en móviles ha tenido éxito. "Supervillanos" o el spin off, ya galardonado con un Emmy, "24H:Conspiracy" han pasado de largo sin respuesta alguna por parte del público.

Aunque los intentos son interesantes en su planteamiento - “24H:Conspiracy” plantea un esquema parecido a su referente en televisión, pero de un minuto de duración cada capítulo. "Prison Break" para móviles ha sido rodado en su mayoría en primeros planos -, el modelo sigue sin funcionar y los mobisodes no dejan de ser un producto de enganche comercial a la operadora o de avance tecnológico que justifique la adquisición de un nuevo terminal.

A todo esto hay que añadir el coste económico que supone la descarga de estos contenidos y que limita aún más el desarrollo de la ficción en móviles. Por el momento no parece muy interesante que por la tercera parte de coste que supone ir una hora y media al cine, "sólo" te ofrezcan un minuto de mobisode. Quizá una estrategia interesante de acceso al producto sería ofrecer en abierto alguna serie para comprobar si éste - el precio - es el factor determinante de la falta de éxito del modelo.

Una circunstancia bien distinta es la utilización del reproductor de vídeo del móvil para ver, en circunstancias de espera o trayectos en medios de transporte público, películas descargadas mediante programas peer to peer y posteriormente comprimidas en 3gp. Esto cada vez tiene más éxito aunque su forma de recepción no sea la más eficaz, pero se conjugan dos razones favorables importantes: una, es gratis; dos, no plantea ningún tipo de ajuste a parrillas de emisión o disposición del emisor sobre el momento en el que se puede o no descargar el producto. Cada uno ve lo que quiere en el momento que quiere y sin pagar, luego, tampoco se puede pedir mayor calidad. A caballo regalado...

El desarrollo de la ficción para móviles debe adaptarse al medio con todas sus peculiaridades. Y en este caso la clave debe ser la complementariedad con otros medios y la exclusividad del contenido con respecto a estos. 
Complementariedad y exclusividad en el sentido de utilizar la micropantalla para ofrecer determinados contenidos que contribuyan al mejor entendimiento de la trama, como explicaciones de acontecimientos que sucedieron fuera de campo, vidas ocultas de personajes, sucesos paralelos..., todo aquello que no exija la misma atención que el argumento central y que otorgue al receptor que ha descargado ese contenido un plus de conocimiento que los demás usuarios no tengan. En el fondo no es más que una extensión del guión, o pequeñas secuelas que fidelicen al telespectador de la serie original.

\subsection{Entretenimiento. Otra vez el cajón de sastre, pero más pequeño.}

El género "todo vale" por excelencia en televisión no lo es menos para este medio. ¿Qué cabe y qué no en este espacio?

No cabe, una vez más, la traslación de los contenidos producidos para la televisión convencional. El recurso más habitual de las operadoras para ofrecer entretenimiento es la selección de los mejores momentos de las series de ficción, de programas de entretenimiento tipo talkshows o reality-shows. Esto, una vez más llena de gris los folletos publicitarios de las compañías que erogan el servicio, pero, rara vez el usuario hace uso del mismo. Quizá el recurso de un "zapping tour" al igual que las tomas falsas, nunca fueron más que pretextos para llenar las parrillas.

Pero lo que sí cabe, sin embargo, son los planteamientos originales. Y en este sentido, cabe apuntar alguna perla que por su originalidad - que no por su dudosa moralidad -, merece ser mencionada.

Se trata del producto gestado por Lechill Mobile y presentado en el 3GSM World Congress de febrero de 2007, "Get into" o, en castellano "Descubre a". Un reality show interactivo ${ }^{24}$.

\footnotetext{
24 "Exclusively developed for mobile phones, where you can follow the life of an interesting person. With 10 weeks for each protagonist, you will be able to follow all their steps. Watch them when they go to parties, meet their friends, see how they work, and meet them at their homes. Every week a new episode is launched. On different occasions, you can ask questions, participate in chats, read their blog and send personal greetings". (Lechill 2007:2)
} 
Realmente se trata de un movlog en el que lo realmente interesante es que no hay guión preestablecido, sino que el producto va construyéndose en función de la interacción de los espectadores con la protagonista, la streapper y actriz porno, Sonia Baby.

Al margen de este tipo de iniciativas, que por otra parte, como ya se apuntó, coinciden con la mayoría de los gustos de los españoles, poco hay en el panorama del entretenimiento, digno de ser mencionado como una propuesta ad hoc del tema que ocupa este artículo.

\subsection{Publicitario. Del esfuerzo de compactar en 20" al milagro de hacerlo en 10.}

En cambio, el mercado publicitario sí va a trastocarse con la irrupción de esta nueva forma de comunicación audiovisual.

La razón específica, el target deja de ser target. Ahora la empresa puede vender su producto uno a uno a cada uno de sus clientes, ya que ahora, al igual que sucedía con el soporte impreso y la dirección de correo física, existe un número único de contacto ¡audiovisual!

Si el doble gran problema de la publicidad audiovisual era la pérdida de eficacia que suponía que el espectador debía ingerir spots que no coincidían en nada con sus intereses consumistas, gustos o preferencias, y que los datos de audiencia que ofrecen los audímetros, no son más que inferencias estadísticas que sirven como estándar diferencial, pero que realmente no dibujan un mapa útil para el anunciante, habría llegado el momento de conseguir que cada espectador de contenidos audiovisuales en el móvil lograse que en su dispositivo sólo entrase publicidad adecuada a sus intereses y que las empresas anunciantes obtuviesen el tan ansiado feed-back.

Son varios los experimentos que se han llevado a cabo en España, destacando el servicio de difusión en segmentación por tramos horarios de mensajes publicitarios vía MMS ofertado por la empresa Lleida.net, o el experimento sobre publicidad audiovisual personalizada cad2mobile $^{25}$.

${ }^{25}$ cad2mobile es el acrónimo de customized advertising to mobile devices. Se trata de un proyecto que se encuentra actualmente en fase de elaboración y que está siendo desarrollado por el Laboratorio de Comunicación Multimedia de 
En mayor o menor grado, estas experiencias atienden a ofertar un tipo de publicidad exclusiva y excluyente que genere en el receptor sentimientos de diferenciación con el resto de la clientela, estado éste que genera elevadas dosis de satisfacción en el receptor y, por ende, de ánimo hacia la compra del producto o de fidelización en la marca.

Existe una disyuntiva sobre cuál es la forma más eficaz de enviar mensajes publicitarios, si vía $M M S$, con coste cero para el receptor, o vía WAP, con coste de descarga para el usuario.

Si la primera de ellas parece la más oportuna, pues aparte del famoso catálogo impreso de decoración de Ikea no existen muchos precedentes de pago por publicidad, esta fórmula constriñe los mensajes a un máximo de diez segundos de vídeo $(100 \mathrm{~kb})$ lo que conduce irremediablemente a un esfuerzo titánico de compactación de conceptos y a una reducción importante de recursos expresivos.

La segunda opción, descarga del spot desde una dirección URL móvil, es más espectacular y da mayor cabida a los contenidos. Sin embargo, ha de luchar con la voluntad del receptor para descargar un anuncio pagando un precio la mayoría de las veces desconocido, el espacio de memoria suficiente en el terminal y la destreza del usuario en la navegación por Internet móvil.

Parece así, la primera de las opciones la que ha de imponerse en el corto plazo, inaugurando una nueva forma de entender la publicidad audiovisual que cambiará la espectacularidad de las producciones por la atención personalizada. Máxime, si como se prevé, las operadoras ofrecerán en un espacio muy cercano de tiempo, el triple de capacidad de envío de archivos multimedia.

Estas opciones de contacto directo con el cliente devendrán en mayores cotas de eficacia y eficiencia comunicativas tanto para el cliente, que por fin verá sólo publicidad interesante, como para el anunciante que tendrá un control garantizado sobre quién ve sus spots, a qué hora, e incluso, en ocasiones, si efectivamente el spot originó una actitud de compra o un aumento significativo de imagen de marca del producto o la empresa.

la Facultad de Comunicación de la Universidad Pontificia de Salamanca. En este experimento se pretende conseguir un sistema por el que a cada cliente le llegue un spot audiovisual expresamente confeccionado para sus intereses de consumo. 


\section{Conclusiones}

Si un observador externo y objetivo atendiese a la publicidad y las campañas de marketing que, acerca de la posibilidad de recibir contenidos audiovisuales en un móvil, se hacen patentes en los medios de comunicación masivos con cierta frecuencia - coincidente con los grandes eventos relacionados con los avances tecnológicos en este terreno -, se encontraría con un panorama más que alentador en el que daría por hecho que la mayor parte de los usuarios de telefonía móvil lo son también de contenidos audiovisuales.

Analizando la realidad, el mapa es distinto. Son pocos los usuarios que utilizan el móvil como reproductor de contenidos audiovisuales, y menos aún, los que reciben y/o difunden archivos de vídeo.

Varias son las razones para que se produzca este desajuste entre lo dicho y lo hecho:

- Los productos que se difunden para ser recibidos en el móvil son meras compresiones o ajustes al formato de vídeo en movilidad (.3gp). No se está contemplando la posibilidad de producir contenidos en exclusividad para el móvil.

- El lenguaje audiovisual que debería observar este nuevo tipo de producción no se está respetando. Si no se "guioniza” para móvil, el producto no conseguirá la eficacia deseada.

- El móvil como soporte no alberga posibilidades de competencia real frente al televisor. Las condiciones de recepción y la calidad de imagen con la que se consumen los productos en los formatos televisivos estandarizados son mejores que las posibilidades que ofrece un dispositivo móvil en los mismos términos de recepción.

- Las estrategias de marketing de las operadoras están enfocadas a la victoria en la batalla de la captación de clientes para sus contratos estándar de voz y SMS. Se está mediatizando el uso de las tecnologías basadas en protocolos IP, pero a cambio no se está ofertando el servicio prometido.

- Las productoras de contenidos audiovisuales están intentando amortizar dos veces el mismo producto - Supervillanos, Homo Zapping... - en vez de crear nuevas producciones ad hoc. 
Así, todo parece apuntar a que el futuro es incierto en lo que a producción audiovisual para movilidad se refiere, y que a la luz, de las estadísticas acerca de los posibles usos, no es aún la estrategia más interesante a tener en cuenta para comunicar audiovisualmente.

Sin embargo, las conclusiones de este artículo quieren proponer justo lo contrario: la producción audiovisual en movilidad es y ha de ser una herramienta diferente y exclusiva de comunicar contenidos singulares y específicos que logarán mayores cotas de eficiencia comunicativa que los contenidos estandarizados, ya que estos últimos se diseminan sobre el público de una forma genérica y alejada de las peculiaridades de cada espectador.

La comunicación audiovisual móvil, como ya se dijo, es la única, hoy por hoy, que permite comunicación individual, exclusiva y excluyente. Esa es su gran fuerza y los productores, operadores y editores deben aprender a aprovecharla, pues de la fuerza de atracción que genera el sentimiento de ser atendido de forma particular, es previsible que crezca un interesante modelo de negocio en el que cabe la ficción, el entretenimiento, la información y, quizás, y por encima de todos, la publicidad.

En definitiva, y siguiendo el símil de las autopistas de la información, en lo que a comunicación audiovisual en movilidad se refiere, aún falta mucho por desarrollar, pero sobre todo, falta dotar de contenidos a estas tecnologías. De nada vale tener autopistas sin lugares a los que viajar. De nada sirve, si hay pocos vehículos, y lo peor, menos valen aún estas vías, si los vehículos que las transitan no están adaptados a este tipo de carreteras.

\section{Referencias bibliográficas}

Domingo Santamaría, D. (2005) “Lenguajes de la comunicación digital”, en VV.AA. Comunicación audiovisual digital, Barcelona: UOC.pp:177-204

Dnx Group Mobile TV. Tendencias en España. Barcelona: DNXGroup.

Galindo Rubio, F.(2005) "El audiovisual en la telefonía móvil. Consideraciones formales para una comunicación eficaz". ZER,. VOL: 19. pp: 127-143

González, Salvador (2006) “Dossier Marketing Móvil”, Interactiva, vol:75 
Huidobro Moya, J.M. y Conesa Pastor, R. (2006) Sistemas de Telefonía. Madrid: Thomson Learning Ibero.

Lechill Mobile (2007) Get Into. Barcelona: Lechill Mobile Press Report.

Negroponte, N. (2000) El mundo digital, Barcelona: Ediciones B,.

Vídeo Popular (2007) “Editorial”, Video Popular, vol: 122. Madrid.

\section{Otras fuentes}

\section{Soporte digital}

Informes on line

Telefónica Móviles.

http://www.vnunet.es/Actualidad/Noticias/comunicaciones/Telefonía/20070309056

Amena.

http://www.20minutos.es/noticia/104612/0/amena/dvb-h/telefonia

Vodafone

http://www.vodafone.es/Vodafone/LaCompanya/NotaSalaPrensa/0,3203,28240,00.html

Blogs

JIMÉNEZ DE LUIS, Ángel. “La tele en el movil”, www.elmundo.es, 13-II-2007.

SANDOBAL, María Pastora. “e-dentidad”, blog: www.mariapastora.cl, Abril 2007.

Webs

http:/ /www.awaves.com/dvbh/flashok.htm disponible el 13/04/07

http://www.periodismo.uchile.cl/ contintanegra/2005/5/blogs.html 
Implicación tecnológica del audiovisual para dispositivos móviles

http://www.elpais.com/yoperiodista

http://www.dvb.org/documents/press-releases

http://www.wireless-world-research.org/

http://www.joost.com

Newsletters

“Newsletter”, vpnews, 2-V-2007 www.videopopular.es

138 | nº 6 | doxa.comunicación 